\title{
Chapter 11 \\ Historical Culture and Peace: How Older \\ Generations Address the Need of Younger \\ Generations to Learn About Their \\ In-Group Past
}

\author{
Giovanna Leone and Mauro Sarrica
}

From birth to death, people are exposed to "an avalanche" (Brescó de Luna \& Rosa, 2012, p. 300) of intergenerational narratives regarding the historical past of the group to which they belong. For each individual, little by little, intergenerational narratives of the in-group's past form an overall perception of "imagined communities", ranging from the small groups they belong to, such as their families, to larger groups such as their nations (Anderson, 2006). These narratives are inserted in a complex infrastructure of many different formal and informal memory devices, meant to make community members share the same historical culture (Grever \& Adriaansen, 2017; Rusen, 1997).

Recent studies on history didactics carried out from an international and interdisciplinary perspective have shown how "the various informal ways of learning in traditional and new popular media - from historical novels, museum exhibitions, heritage sites, to films, television shows and documentaries, website and apps have intensified the general attractiveness of history" (Carretero, Berger, \& Graver, 2017 , p. 1). It implies that currently, in many societies around the world, history seen as a subject of formal teaching - is being conveyed in increasingly hybrid forms. Thanks to these new hybrid forms, inextricably combining both formal teaching and informal communication about the past, adult members of a community gradually scaffold the development of the historical consciousness of new born individuals, allowing them to collapse the perception of their current "we" with the historical "we" that was narrated to them. This process builds for younger generations a kind of "imagiNation" (Carretero, 2017) that ensures a sense of continuity and entitativity of nations across generational changes. Together with these in-group aims, narratives of the historical past also fulfil aims linked to intergroup relations (Mazzara \& Leone, 2001). When intergroup relations are negative, intergenerational

G. Leone $(\bowtie) \cdot$ M. Sarrica

Sapienza University of Rome, Rome, Italy

e-mail: giovanna.leone@uniroma1.it; mauro.sarrica@uniroma1.it 
narratives and collective memories have been largely studied as pivotal elements used to fuel intergroup hostility and distrust, to socialise new generations into an ethos of conflict and to justify the continuation of cycles of violence and of longstanding conflicts (Coleman, 2003; Tint, 2010).

Our proposal is framed in a more comprehensive description of society, focusing on societal changes rather than specific in-group or intergroup relations. Such a framework was introduced in the pioneering work of Hannah Arendt $(1958,1977)$. According to her unconventional and innovative lesson, societal changes are best described by taking into consideration the lifecycle of ordinary people, rather than referring to individual creativity or other special capacities of extraordinary men. By introducing the new concept of natality at the very core of societal changes, Arendt (1977) argued that the real source of novelty in social life is linked to the fact that each birth represents a new beginning for the community. Certainly, newborn individuals receive the world in which they live from older people; however, moving from this prearranged starting point, the reactions of younger individuals to the historical responsibilities of their in-group may contribute towards building and improving peaceful intergroup relations (Cairns \& Roe, 2003; Kelman, 2008; Nadler \& Shnabel, 2008). By introducing the concept of natality, and placing it at the very core of societal changes, Arendt argued, therefore, that each birth represents a new beginning for the community (Arendt, 1958, 1977).

Arendt's theoretical perspective is still innovative, since researches looking at peace building as an intergenerational task are usually aware of aspects of continuity between generations, more so than discontinuities occurring when older generations give room for change to younger ones (Leone, 2018). In fact, young citizens may use their individual historical consciousness, embedded in a larger societal historical culture (Rusen, 1997), not only to protect their positive social identity (Tajfel, 1982) but also to become more aware of moral failures and shortcomings of older generations. In this sense, the "avalanche" of intergenerational narratives may be seen not only as a source of a feeling of historical continuity with past generations but also as a springboard for change. More particularly, group-based emotions of moral shame, due to a deep understanding of historical failures of past generations, may enhance a young person's capacity to enact discontinuities and changes from old choices and habits.

The aim of our chapter is to defend the idea that, when acting in favour of reconciliation, the risk of making the descendants of groups involved in past violence deeply ill at ease, while thinking about their violent historical past, is worth taking. In order to make this point we will review classic studies which have shown that historical awareness is not only an important cultural tool but also a crucial need of younger generations, especially when they have to cope with a troubled past. Then we will describe situations in which intergenerational communication fails and silence and social denials are used instead. Finally, we will describe peace in the frame of intergenerational communication and we will draw some tentative conclusions and propose directions for research and intervention. 


\subsection{The Need of Young Generations to Learn About Their In-Group past}

Often at times, the idea that young people are indifferent to history and are only embedded in present days is presented as common sense. On the contrary, many important classic studies have shown that learning about their in-group's historical past is a basic socio-psychological need for young people coming of age and starting to cope with their adult responsibilities in the democratic forum. ${ }^{1}$

A first and fundamental example on the precious contribution of history to enhance the full development of democratic societies is offered by the classic book The Historian's Craft or Apology of History (Bloch, 1954). Bloch wrote this unfinished masterpiece referring only to his own memory, shortly before being executed in 1944 as a leader of the French resistance. Bloch chose to build the whole of his little but classic book around a hypothetical question posed by his 12-year-old son after the sudden shock following the conquest of Paris by the Nazi troops: "What is the use of history?" Using this literary fiction, Bloch explained to his son that the function of historical accounts is not to provide advice or strategic counselling in dangerous times, but to comply with a basic law of the human mind, namely, to fulfil its "instinctive need of understanding". Especially in dark historical times, in the intimacy of their communications, families participate in a neverending collective effort to give meaning to the historical events they have to face. Without taking into account this activity of human mind, it is impossible to understand the impact of historical facts on society. The recounting of history helps individuals assign meaning to what happened in the past and sets the stage for how they choose to conduct their lives going forward (Sweeny, 1993).

In these same dark years, another influential French scholar, Maurice Halbwachs, focused his attention on family narratives of the past. Halbwachs (1925/1992) decided to observe what happens when family members gather together to remember ("quand la famille se souvient"). He noted how, in the intimate setting of their faceto-face conversations, families repeatedly narrated some specific episodes, chosen from among several that had occurred in the family's past. Sometimes, shared memories would recollect specific historical events. At other times, these family narratives would convey to younger members recollections of past ways of living that had been experienced by the older generations but were subsequently gone. Although knowing them by heart, family members listened with evident pleasure to these over-narrated episodes and seemed to cherish them as a kind of family treasure. By contrast, these same memories were not shared with strangers. In his seminal books, Halbwachs (1925/1992, 1950/1980) proposed that repeated family memories supported the personal positive identity of younger generations. By repeatedly

\footnotetext{
${ }^{1}$ Interestingly, European scholars strongly addressed this point during the first decades of the past century, when they struggled to understand the dramatic social situations in which they were living. In spite of being deeply different from each other, all these scholars understood the importance of narratives of their dramatic in-group history to young individuals and the protective role that intergenerational communication play in the dark times they had to live.
} 
sharing family memories that were not told to strangers, families were gifting to their younger members a positive image of the nucleus from which they originated and therefore of the fabric of which all of the family members were made - an "emotional armour" aimed at protecting them in the future when they needed to cope with life's difficulties.

Also in the same period, Ortega y Gasset, addressed the issue of intergenerational narratives on the in-group past in his masterpiece The Revolt of the Masses. He described the troubling cultural disease by which European crowds were changing into masses prone to dictatorship and pointed out that the "strange condition of human person" is "his essential pre-existence". That is that the lives of humans do not begin with their birth but are pre-shaped by the history of their community. Although being fully aware of the historicity of humans, however, Ortega y Gasset argued that the past of the community in which a person happens to be born "instead of imposing on us one trajectory ... imposes several, and consequently forces us to choose" (Ortega y Gasset, 1930/1957, p. 31; emphasis added). Refusing any positivistic attitude, Ortega described therefore intergenerational historical narratives not as inescapable burdens, but as basic tools for fostering young adults' decisions, enabling them to grasp their starting points in life. According to the idea of historical pre-existence of the human mind (Ortega y Gasset, 1930/1957), intergenerational narratives of past historical times are offered to young people as cultural keys to understand their current social positions. By enhancing the historical awareness of the younger ones about their in-group past, older generations also allow them to better choose how to act in the social arena.

\subsection{Silence and Self-Denials of Older Generations}

The seminal thoughts briefly described in the previous paragraph give us an idea of the importance of young boys and girls reminiscing together with the older generation. New generations integrate single episodes into life stories and autobiographies, acquire culturally shared interpretative frameworks and master narratives and anchor individual episodes to family history and the larger sociocultural events (Fivush, Habermas, Waters, \& Zaman, 2011; Reese \& Fivush, 2008). Older generations, on the other hand, build a positive social identity (Tajfel, 1982) and introduce children to historical consciousness. Living with grandparents and listening to their narratives, in fact, provide children with "a rich base of information about the fundamental structures and processes of everyday life during those (past) times" (Seixas \& Peck, 2004, p. 115), creating the first scaffolding for the later development of their capacity for historical thinking (Seixas \& Peck, 2004; Seixas, 2017).

It is thus a puzzling experience for a young boy or a young girl to find something like a photograph of the war period, a "souvenir" of colonies, or maybe a gun well hidden in the old grandparent's closet. The old object gives a clue to instantly reconnect individuals and their close family to the major events that make history 
(assuming that we are in a culture where wars make history more than peace). At the same time, such discoveries create a fracture between the new generation and the previous one. Clearly, the previous generation may have decided to not share part of their history and may have wanted to create some distance between their times and the experiences of future generations.

In fact, when older generations convey to younger ones the thrust of their historical past, the acknowledgement of historical responsibilities accounting for past violence can be an important milestone in intergroup reconciliation (Vollhardt \& Bilewicz, 2013). The use of conflict-driven narratives in long-standing conflicts has been largely examined: active cultivation of group perception and memories, as well as selective omissions, perpetuate emotions, keep past events alive, maintain a sense of menace to in-group survival, forge social identities and, finally, develop a conflictive ethos (Bar-tal, 2000; Tint, 2010). However, when intergroup violence comes to an end, a symbolic struggle regarding moral responsibility opens up. This struggle, which may last for a long time, aims to disambiguate, beyond all complexities inherent to any historical judgement, which role can be attributed to one's own group during aggressive incidents - be it either the role of perpetrators, or the role of victims or, finally, the less evident but very influential role of passive bystanders (Leone, in press). Although apparently protecting younger generations from groupbased moral emotions - such as guilt, moral shame or social shame (Allpress, Brown, Giner-Sorolla, Deonna, \& Teroni, 2014) - narratives based on silence and denial avoid conveying the crucial role played by the in-group in past violence and are important moral failures that slow down the process of intergroup reconciliation (Hameiri, Bar-Tal, \& Halperin, 2017).

\subsubsection{Why Do Older Generations Keep Troubled Memories Hidden?}

Psychoanalytic, social cognition and constructivist perspectives, though starting from different premises, give many possible answers, which are deeply rooted in individual and group self-protective needs (Cohen, 1993). A critical approach to silence suggests linking this communicative act with power. In this regard, Fivush distinguishes between the choice of being silent and the fact of being silenced (Fivush, 2010). Whereas the first choice could be considered an expression of control and mastery of the situation - in a single phrase we may say "an act of power" - the fact of being silenced by self or others is virtually always seen as a lack of power. As Fivush (2010) underlines, silence could derive from conformity with the shared cultural scripts, which does not require justification and explanations. Silence can also be used in social interaction to impose distance, to reduce the importance of the others, to express judgement. Finally, being silent together could create a space of belonging and emotional attunement. In these three cases, silence is an expression of conformity, power and empowerment, respectively. 
On the one hand, silence can be imposed on new generations as a deliberate act of power, an active choice of elites and states in constructing symbologies and technologies aimed at perpetuating cultural, structural and even direct forms of violence (Liu, Fisher Onar, \& Woodward, 2014). Constructionism underlines how societies select their memories on the basis of their current needs, beliefs and goals and choose traumas and glories in order to transmit values, emotions and shared beliefs together with history (Tint, 2010, p. 242-243). Silence over human right violations committed by the in-group exemplifies this (Paez \& Liu, 2009; Paez, Marques, Valencia, \& Vincze, 2006).

On the other hand, imposed or self-imposed silence expresses deviation and disempowerment. These types of silencing may occur in response to violent traumas, war memories or negative events that threaten individual and social identity. Silence, in these cases, may be due to the perceived or actual lack of an audience that wants to, or can, understand stories that seem unintelligible or unbearable because they deviate so much from shared narratives. Organised manipulation of history is not even necessary when speakers perceive that their stories are too deviant to be understood and accepted by their audience or even by themselves or when they are too weak or socially isolated to have voice. Under these conditions, denial is a banal occurrence.

Psychoanalytic and social cognitive perspectives associate denial with this form of culturally self-imposed silence: a self-defensive mechanism towards threats. From a social cognition perspective, in particular, silencing is interpreted in terms of basic memory processes (e.g. forgetting, selective recall, assimilation), which contribute to self-serving and group-serving biases (Allport \& Postman, 1945). Through the processes of complete denial or through more subtle omissions, individuals distance themselves or reject past events that they or their in-group can't manage. It is a non-adaptive form of coping, which fulfils the basic individual and group need to manage unbearable memories and preserve a positive identity and at the same time limit the capacity to develop more complex and critical accounts of these facts.

Together with complete silence, more subtle forms of neutralisation techniques can be used to cope with past wrongdoings. Cohen (1993) identifies five common techniques of denial that manifest in shared rhetorical discourses: "no one was affected", i.e. denial of injuries; "it's their fault", i.e. denial of the role of victims; "they are just as bad", i.e. denial of the legitimacy of judges; "we had to do it", i.e. denial of responsibility; and "it was us versus them", i.e. appeal to shared loyalty.

In order to make these techniques acceptable to audiences, narratives must refer to a "cultural pool of motivational vocabularies available to actors and observers (and honoured by systems of legality and morality)" (Cohen, 1993, p. 107), which are based on implicit disempowerment of self and others. Examples of these narratives in intergenerational communication include the need to "protect the new generations" assuming they cannot bear the truth, the idea that "time will pass and solve conflicts" implicitly accepting the fact that perpetrators and victims don't have the capabilities to solve them and the idea that "it's better to forget" because there is no other way to cope with the past. 
Furthermore, these same rhetorical devices can contribute in the long term to establishing a new shared pool of vocabularies and "states of denial" (Cohen, 2001) that fulfil self-protective needs and at the same time hinder the emergence of mutual trust, acceptance and empowerment of victims and perpetrators. The literal denial ("it didn't happen") contributes to create and preserve positive social identity based on idealised historical past and social myths, like the myth of "Italian as good fellows" (Volpato, Andrighetto, Mari, Gabbiadini, \& Durante, 2012). Through interpretative denial, the roles of victims and perpetrator are reframed in more acceptable ways ("... we are not responsible"), which however imposes silence on the causes and actors of wrongdoing. Lastly, the implicatory denial is a refusal to assume the consequences of one's own responsibility ("we admit our responsibilities ... now you -the victim- must forget and forgive"), which, again, imposes silence on the victims who are not left free to speak for themselves and express their own needs.

\subsection{Peace as an Intergenerational Task}

The different forms of silence and denial of perpetrators, bystanders and victims described in the previous paragraphs are apparently functional in restoring the surface of everyday coexistence. In the long run, however, if self-protective narratives become dominant in a community, then both imposed and self-imposed choices of silence hinder reconciliation processes (Kelman, 2008). Well-known processes such as the "spiral of silence", avoidance of intergroup contact and polarisation of collective identities preserve elements that foster, beneath the surface, long-standing intractable conflict (Coleman, 2003; Halperin \& Bar-Tal, 2011). Examples of these dynamics can be found in the rhetoric of Thanksgiving day (Kurtiş, Adams, \& Yellow Bird, 2010), the "forgotten" Armenian genocide (Bilali, 2013; Hovannisian, 1998), the silence over collaboration during the regime of Vichy (Campbell, 2006) and the social amnesia about the Italian colonial crimes (Leone \& Sarrica, 2012, 2014).

On the contrary, addressing the past and developing shared views is increasingly recognised as fundamental to reconciliation processes. According to the theoretical model proposed by Nadler and Shnabel (2008, 2015), groups involved in past violence have to face different identity threats. Perpetrators have to cope with a failure that undermines the moral image of their group and makes their social exclusion highly probable. Victims have to face their evident incapacity to control their own destiny, which is another kind of failure of their social image (Landsman, 2002). Finally, narratives of former violence can trigger serious group-based emotions in descendants of passive bystanders as well, since avoidance of solidarity towards victims implies a moral responsibility too (May, 2011). According to this theoretical proposal, for instance, a work of Wojcik, Bilewicz, and Lewicka (2010) in this somehow underdeveloped field of study has shown that descendants of 
bystanders born in communities where massive violence occurred were eager to learn the history of their town.

Thanks to the scaffolding of a historical culture passed from older generations to newer ones, group-based emotions of guilt, moral and social shame associated with past violence go down the generations and can also be felt by descendants born long after the end of intergroup violence (Allpress et al., 2014; Shepherd, Spears, \& Manstead, 2013). This means that intergenerational recollections of past historical responsibility of one's own group for past violence - either enacted, or suffered, or indifferently witnessed - inherently produce a loss for the moral image of the group and a consequent process of social mourning (Adorno, 1986). Nevertheless, if responsibilities of one's own group are not fully and clearly stated for young listeners, intergenerational narratives about past intergroup violence cannot produce their positive effects that build and consolidate peaceful relations between old enemies (Cairns \& Roe, 2003; Tint, 2010).

\subsubsection{Peace as an Intergenerational Task}

Surprisingly, very few studies have explored the societal struggle between the choice of silence and the decision to speak frankly about the past to new generations.

\subsection{Breaking the Silence on Italian Colonialism: An Applied Example}

A few studies have shown that young generations react emotionally to the historical knowledge of past responsibilities of their in-group even many years after these events and that moral emotions felt by them seem to encourage their reparative intentions towards the former victims. For instance, experimental studies were conducted to observe how Italian university students reacted when presented with either a clear and detailed or a mild historical account of violence enacted by the Italian Army during the colonial invasion of Ethiopia, which occurred during the Fascist regime. During this campaign, Italian troops used poisonous gas against the enemy, despite its prohibition by the Geneva Convention. Ethiopian resistance continued after the official end of the war, and Italian repression was cruel, particularly in response to a failed assassination attempt on Governor Graziani in 1937, when some six thousand civilians - according to Western sources - were executed, among them somewhat roughly three hundred monks of Debre Libanos.

Until recently, these crimes were socially denied. When finally proven beyond any doubt by an Italian history scholar (Labanca, 2002), they nevertheless remained silenced in social discourse. Italian history textbooks have only recently begun to explore this issue (Leone \& Mastrovito, 2010; Cajani, 2013), but still present it as a 
short period intrinsically linked solely to the Fascist regime. Moreover, many images used in contemporary textbooks are taken from Fascist propaganda or from booklets for children (Leone, 2018). Thanks to this kind of societal self-censorships, these war crimes are still largely ignored in general social discourse (Pivato, 2011; Leone \& Curigliano, 2009).

Moreover, the Italiani brava gente historical myth, depicting the Italian people as good and generous both in everyday life and in the military context, is still widely circulating (Del Boca, 2005). The social myth belies the brutality of Italian colonialism.

To explore how historical narratives could finally open up the Pandora box of these difficult group memories, a plan of experimental studies was set in place (Leone, d'Ambrosio, Migliorisi, \& Sessa, 2018; Leone, Giner-Sorolla, D'Errico, Migliorisi, \& Sessa, 2018; Leone \& Sarrica, 2012; Leone \& Sarrica, 2014). A part for specific aims of each experiment, all studies were conducted using a same procedure, organised into three different moments: time zero (T0), time one (T1) and time two (T2). The scheme repeatedly used for procedures ran as follows:

At (T0), each participant (young Italian university students) received a preliminary questionnaire, focused on knowledge and social representation of Italian colonialism, self-assessed emotions when thinking about this period of Italian history and assessed belief in the social myth describing Italians as good types (i.e. Italiani, brava gente (IBG): see Del Boca, 2005).

At (T1), after collecting the questionnaire, a researcher invited the participant to read the text shown on a computer screen on the desktop in front of which he/she was sitting and then to follow further instructions shown on the screen. After giving these instructions, the researcher left the room. Each participant was randomly assigned to read either an explicit ("poisonous gas" "mass killings") or implicit ("unconventional weapons" "attempts at repression") text. Participants were covertly videotaped while reading. Emotions on Italian colonialism were again self-assessed.

Finally at (T2) after a week and before receiving a debriefing, knowledge and understanding of the text was tested and the manipulation was checked. Then participants self-assessed for the third time their emotions (including moral emotions) about Italian colonialism and declared their agreement, if any, with reparative actions.

Apart from specificities linked to single studies, all the experimental evidence collected pointed to some regular patterns. Results at T0 showed that young Italian participants seemed to be unaware of Italian colonial crimes. Moreover, they expressed very low levels of intergroup emotions when thinking about Italian colonisation and declared their indifference to the social myth depicting the Italian people as good and generous types (Del Boca, 2005). Taken together, T0 results suggested that the Italian colonial past was not felt as "psychologically contemporary" by young participants (Lewin, 1943).

When experimenters analysed the facial expression of emotions shown by students covertly videotaped when reading, they observed how participants showed 
facial expressions of primary emotional reactions. It is interesting to stress that, being alone, their facial reactions could not be attributed to communicative intention but solely to their first appraisal of the seriousness of facts they were informed of. Emotions more often spontaneously shown by these young participants unaware of being observed were sadness and contempt.

When coming to the issue of self-assessed emotions, a comparison between $\mathrm{T} 1$ (immediately after reading the historical text on societally censored past colonial crimes) and T2 (a week later), all experiments showed that negative emotions significantly increased while reading the clear and detailed text on war crimes by the Italian Army. More specifically, if we take into account the self-conscious moral emotions (guilt, social shame, moral shame, pride), shown after 1 week, social and moral shame significantly increased and pride significantly decreased only for those young people receiving a clear historical narrative of the crimes committed by previous generations. These emotions, based on a change of their image of the group, could perhaps account for a moral loss of a positive idea of their historical identity, due to the awareness of past crimes that were until then kept silent in the social discourse they received about this period of the Italian national past.

Finally, and interestingly, the more recent among these researches (Leone, d'Ambrosio, et al., 2018) has shown how reparative intentions were positively associated only with the self-conscious emotions of social and moral shame, yet not with guilt.

Taken together, the results of this line of experimentation showed that when historical narratives break down literal social denials, only a clear account of past responsibilities of the in-group can be fully understood by young people previously unaware of this historical past and can lead to the expression of reparative intentions by young participants.

Of course, these empirical data (Leone, d'Ambrosio, et al., 2018; Leone, GinerSorolla, et al., 2018; Leone \& Sarrica, 2012; Leone \& Sarrica, 2014) also show how a clear historical narrative about the flawed moral character of one's own group that was heretofore denied or silenced can be a discomforting experience. Nevertheless, for those who are able to regulate themselves (Frijda, 1986), negative group-based emotions linked to this new awareness of moral indignities of one's own group seem to be powerful motivators of collective moral action (Smith, 1993).

In a nutshell, we can use the example of these data on societal self-censorship of Italian colonial crimes to suggest that, after a long intergenerational silence on past violence, a clear and frank account on crimes of the group formerly silenced or denied can be a way to open the Pandora's box of these past wrongdoings.

\subsection{Concluding Remarks}

It is possible to apply Foucault's original taxonomy of various forms of truth speaking (Foucault, 2001) to the issue of intergenerational narratives regarding the national past as well as communications about other kinds of difficult truths (a 
severe diagnosis, a negative law judgement, a school failure). In addition, those who speak clearly to young people on past historical responsibilities of the nation in which they happen to be born are implicitly showing their confidence in their receivers' strength and moral judgements. According to the taxonomy proposed by Foucault (2001), we may say therefore that when members of an older generation frankly narrate a shameful national history to a younger generation born after the end of these events, they are speaking to younger members with parrhesia. It means that, by choosing to tell them an uneasy truth, they are also showing an implicit trust in their receivers' capacity to cope with this difficult and harrowing knowledge.

Both classic theoretical models and recent experimental research suggest that this choice of parrhesia in intergenerational narratives of a shameful historical past may enhance reconciliation processes and peace. However, empirical research shows that different historical cultures choose to be less than completely clear about past atrocities of an in-group. It may well be that older generations could adopt this hidden communicative strategy when they suspect that descendants of the social groups that were involved will react negatively to their message (Gross, 1998).

Much more empirical research has to be done therefore to observe the way in which older generations foresee young generations' reactions to their historical accounts and choose parrhesia or an evasive form of communication. Research is also needed, then, to examine how young people regulate and evaluate the direct or evasive historical narratives that are passed on to them by older generations. This future direction of work could greatly add to our understanding of intergenerational processes that allow social groups to renew their relations. Nevertheless, the studies we presented in this chapter already point out a few key actions which can be considered for peace building based on the difficult intergenerational mourning for the moral losses of the past.

\subsection{Application to Policy and Practice}

We started this chapter noting that we all have been exposed to "an avalanche" (Brescó de Luna \& Rosa, 2012, p. 300) of intergenerational narratives on the historical past of our in-groups. These narratives include formal and informal sources, memory devices, schools, media, family members, etc. which operate as interdependent components of a same societal process (cfr. Carretero et al., 2017; Grever \& Adriaansen, 2017; Rusen, 1997). The following suggestions, which refer to the family, may be applied to a variety of formal and informal sources of intergenerational narratives.

- Leverage new generations' need for knowledge. Classic and recent studies show that learning about family and in-group historical past is a basic sociopsychological need, which allows new generations to position the self and the family group in a broader historical context. This "armour" is key to personal and social identity and to understanding current events. Following Ortega y Gasset 
(1930/1957) it is important to acknowledge this historical pre-existence of the human mind refusing at the same time any determinism. Intergenerational narratives should be offered to young people as cultural keys, enhancing their historical awareness about the in-group's past and allowing them to better choose how to act as adults and citizens in a democratic forum.

- Challenge conflictive master narratives. History absorbed by children from the family (and other sources) is usually affected by self-serving bias, which forges positive social identities - and in some cases real conflict ethos - through active cultivation of memories and through forms of self-censorship and denial (BarTal, 2000; Cohen, 2001; Hameiri et al., 2017; Tint, 2010). These narratives further expose new generations to a range of group emotions, including guilt, moral and social shame. Epistemic authorities (e.g. the grandparents, teachers) should thus challenge master narratives, deconstructing myths (Volpato et al., 2012) that are often based on self-indulgency. It means that intergenerational narratives, when honestly trying to inform young people about events that happened before their birth, have to strongly avoid illusions of moral superiority of the in-group and frankly speak about its historical responsibilities.

- Regulate Group-Based Emotions. Being exposed to previously hidden historical responsibility of one's own group for past violence - either as perpetrators, victims or bystanders - produces a loss of moral image for the group. In our research example, we have reviewed a long line of experimental studies exploring reactions of descendants of perpetrators, when becoming aware of the crimes committed by older generations. These crimes were kept silent by a massive societal self-censorship. But similar reactions could be expected also when descendants of victims are told about violence suffered by older generations. Unlike perpetrators who struggle with the difficulty of acknowledging their culpability, victims struggle to develop a sense of empowerment (Nadler \& Shnabel, 2015). In both of these cases, it is essential for the younger generation to be aware of intergenerational narratives in order to proceed on the path of real intergroup reconciliation. There are risks however: When older generations are in the position of disclosing to younger people their historical past, there is the risk of producing very unpleasant effects (Leone, 2017).

The socio-psychological perspective stresses the idea that group-based emotions should not be avoided in the name of pure rationality (which is impossible). On the contrary, it is important to develop emotion regulation abilities, which permit spontaneous reactions while at the same time enhancing their positive expression and their use as a resource for cognitive processes. Formal settings, such as schools, present an opportunity for teachers to discuss sensitive issues surrounding the historical past (Brauch, Leone, \& Sarrica, 2019), drawing on emotions stemming from a history of violence and encouraging young people to use this opportunity to once again hope and act for peace. 


\section{References}

Adorno, T. (1986). What does coming to terms with the past mean? In G. Hartman (Ed.), Bitburg in moral and political perspective (pp. 114-129). Bloomington, IN: Indiana University Press.

Allport, G. W., \& Postman, L. J. (1945). Section of psychology: The basic psychology of rumor. Transactions of the New York Academy of Sciences, 8(2 Series II), 61-81.

Allpress, J. A., Brown, R., Giner-Sorolla, R., Deonna, J. A., \& Teroni, F. (2014). Two faces of group-based shame: Moral shame and image shame differentially predict positive and negative orientations to in-group wrongdoing. Personality and Social Psychology Bulletin, 40(10), $1270-1284$.

Anderson, B. (2006). Imagined communities: Reflections on the origin and spread of nationalism. New York \& London: Verso Books.

Arendt, H. (1958). The human condition. Chicago, IL: University of Chicago Press.

Arendt, H. (1977). Between past and future: Eight exercises in political thought. London: Penguin Books.

Bar-Tal, D. (2000). From intractable conflict through conflict resolution to reconciliation : Psychological analysis. Political Psychology, 21(2), 351-365.

Bilali, R. (2013). National narrative and social psychological influences in Turks' denial of the mass killings of Armenians as genocide. Journal of Social Issues, 69, 16-33.

Bloch, M. (1954). The Historian's craft or apology of history. New York: Knopf.

Brauch, N., Leone, G., \& Sarrica, M. (2019). The debate almost came to a fight...'results of a cross-national explorative study concerning history teachers' shared beliefs about teaching historical sensitive issues. Pedagogy, Culture \& Society, 27(1), 1-22.

Brescó de Luna, I., \& Rosa, A. (2012). Memory, history and narrative: Shifts of meaning when (re) constructing the past. Europe's Journal of Psychology, 8, 300-310.

Cairns, E., \& Roe, M. D. (Eds.). (2003). The role of memory in ethnic conflict. New York: Palgrave Macmillan.

Carretero, M. (2017). Teaching history master narratives: Fostering imagi-nations. In Palgrave handbook of research in historical culture and education (pp. 511-528). London: Palgrave Macmillan.

Carretero, M., Berger, S., \& Graver, M. (Eds.). (2017). Palgrave handbook of research in historical culture and education. London: Palgrave Macmillan.

Campbell, J. (2006). Vichy, Vichy, and a plaque to remember. French Studies Bulletin, 27(98), 2-5.

Cohen, S. (1993). Human rights and crimes of the state: The culture of denial. Australian \& New Zealand Journal of Criminology, 26, 97-115.

Cohen, S. (2001). States of denial: Knowing about atrocities and suffering. Cambridge, UK: Polity Press.

Coleman, P. T. (2003). Characteristics of protracted, intractable conflict: Toward the development of a Metaframework - I. Peace and Conflict: Journal of Peace Psychology, 9, 1-37.

Cajani, L. (2013). The Image of Italian Colonialism in Italian History Textbooks for Secondary Schools. Journal of Educational Media, Memory, and Society, 5(1), 72-89.

Del Boca, A. (2005). Italiani, brava gente? Un mito duro a morire. Vicenza: Neri Pozza.

Fivush, R. (2010). Speaking silence: The social construction of silence in autobiographical and cultural narratives. Memory, 18, 88-98.

Fivush, R., Habermas, T., Waters, T. E. A., \& Zaman, W. (2011). The making of autobiographical memory: Intersections of culture, narratives and identity. International Journal of Psychology/ Journal International de Psychologie, 46, 321-345.

Foucault, M. (2001). Fearless Speech. Los Angeles: Semiotext(e)..

Frijda, N. H. (1986). The emotions. London: Cambridge University Press

Grever, M., \& Adriaansen, R.-J. (2017). Historical culture: A concept revisited. In M. Carretero, S. Berger, \& M. Graver (Eds.), Palgrave handbook of research in historical culture and education (pp. 73-89). London: Palgrave Macmillan. 
Gross, J. J. (1998). The emerging field of emotion regulation: An integrative review. Review of General Psychology, 2(3), 271-299.

Halbwachs, M. (1925/1992). On Collective Memory. Chicago, IL: University of Chicago Press. (Translated abstracts from: Les cadres sociaux de la mémoire, Paris, Librairie Alcan.)

Halbwachs, M. (1950/1980). The collective memory. New York: Harper \& Row.

Halperin, E., \& Bar-Tal, D. (2011). Socio-psychological barriers to peace making: An empirical examination within the Israeli Jewish society. Journal of Peace Research, 48, 637-651.

Hameiri, B., Bar-Tal, D., \& Halperin, E. (2017). Self-censorship as a socio-psychological barrier to peacemaking. In D. Bar-Tal, R. Nets-Zehngut, \& K. Sharvit (Eds.), Self-censorship in contexts of conflict (pp. 61-78). Cham, Switzerland: Springer.

Hovannisian, R. G. (1998). Remembrance and denial: The case of the Armenian genocide. Detroit, MI: Wayne State University Press.

Kelman, H. C. (2008). Reconciliation from a social-psychological perspective. In A. Nadler, T. E. Malloy, \& J. D. Fisher (Eds.), The social psychology of intergroup reconciliation (pp. 15-32). New York: Oxford University Press.

Kurtiş, T., Adams, G., \& Yellow Bird, M. (2010). Generosity or genocide? Identity implications of silence in American Thanksgiving commemorations. Memory, 18, 208-224.

Labanca, N. (2002). Oltremare: Storia dell'espansione coloniale italiana (Vol. 31). Bologna, Italy: Il Mulino.

Landsman, I. S. (2002). Crises of meaning in trauma and loss. In J. Kauffman (Ed.), Loss of the assumptive world: A theory of traumatic loss (pp. 13-30). New York \& London: Brunner- Routledge.

Leone, G. (2017). When history teaching turns into Parrhesia: The case of Italian colonial crimes. In C. Psaltis, M. Carretero, \& S. Čehajić-Clancy (Eds.), History education and conflict transformation (pp. 147-167). Cham, Switzerland: Springer.

Leone, G. (2018). Beyond historical guilt: Intergenerational narratives of violence and reconciliation. In A. Rosa \& J. Valsiner (Eds.), The Cambridge handbook of sociocultural psychology (pp. 458-478). Cambridge, UK: Cambridge University Press.

Leone, G., d'Ambrosio, M., Migliorisi, S., \& Sessa, I. (2018). Facing the unknown crimes of older generations: Emotional and cognitive reactions of young Italian students reading an historical text on the colonial invasion of Ethiopia. International Journal of Intercultural Relations, 62, $55-67$.

Leone, G., Giner-Sorolla, R., D’Errico, F., Migliorisi, S., \& Sessa, I. (2018). It's time to be ashamed! Reactions to the breaking of a long-lasting self-censorship on ingroup war crimes. TPM: Testing, Psychometrics, Methodology in. Applied Psychology, 25(4), 519-535.

Leone, G., \& Sarrica, M. (2012). Challenging the myth of Italians as 'good fellows': Is clarity about in-group crimes the best choice when narrating a war to its perpetrators' descendants ? Papers on Social Representations, 21, 11.1-11.28.

Leone, G., \& Sarrica, M. (2014). Making room for negative emotions about the national past: An explorative study of effects of parrhesia on Italian colonial crimes. International Journal of Intercultural Relations, 43, 126-138.

Liu, J. H., Fisher Onar, N., \& Woodward, M. W. (2014). Symbologies, technologies, and identities: Critical junctures theory and the multi-layered nation-state. International Journal of Intercultural Relations, 43(A), 2-12.

Leone, G., \& Curigliano, G. (2009). Coping with collective responsibilities An explorative study on Italian historical identity across three generations. Journal of Language and Politics, 8(2), 305-326.

Leone, G., \& Mastrovito, T. (2010). Learning about our shameful past: A socio-psychological analysis of present-day historical narratives of Italian colonial wars. International Journal of Conflict and Violence, 4(1), 11-27.

Lewin, K. (1943). Defining the 'field at a given time'. Psychological Review, 50(May (3)), 292-310.

May, L. (2011). Bystanders, the rule of law, and criminal trials. Nomos, 50, 241-264. 
Mazzara, B. M., \& Leone, G. (2001). Collective memory and intergroup relations. Revista de Psicologia Social, 16(3), 349-367.

Nadler, A., \& Shnabel, N. (2008). Instrumental and socioemotional paths to intergroup reconciliation and the needs-based model of socioemotional reconciliation. In A. Nadler, T. E. Malloy, \& J. D. Fisher (Eds.), The social psychology of intergroup reconciliation (pp. 37-56). New York: Oxford University Press.

Nadler, A., \& Shnabel, N. (2015). Intergroup reconciliation: Instrumental and socio- emotional processes and the needs-based model. European Review of Social Psychology, 26(1), 93-125.

Ortega y Gasset, J. (1930/1957). The Revolt of the Masses. New York: W. W. Norton. (Originally published as La rebelión de las masas.)

Paez, D., \& Liu, J. H. (2009). Collective memory of conflicts. In D. Bar-tal (Ed.), Intergroup conflicts and their resolution: Social psychological perspective (pp. 105-124). Hove and New York: Psychology Press.

Paez, D., Marques, J., Valencia, J. F., \& Vincze, O. (2006). Dealing with collective shame and guilt. Psicologia Politica, 32, 59-78.

Pivato, S. (2011). Vuoti di memoria: usi e abusi della storia nella vita pubblica italiana. BariRoma, Italy: Laterza.

Reese, E., \& Fivush, R. (2008). The development of collective remembering. Memory, 16, 201-212.

Rusen, J. (1997). "Geschichtskultur" ["Historical Culture”]. In K. Bergmann (Ed.), Handbuch der Geschichtsdidaktik [handbook of the didactics of history] (pp. 38-41). Seelze-Velber: Kallmeyer'sche Verlagsbuchhandlung.

Seixas, P., \& Peck, C. (2004). Teaching historical thinking. In A. Sears \& I. Wright (Eds.), Challenges and prospects for Canadian social studies (pp. 109-117). Vancouver, Canada: Pacific Educational Press.

Seixas, P. (2017). Historical consciousness and historical thinking. In M. Carretero, S. Berger, \& M. Graver (Eds.), Palgrave handbook of research in historical culture and education (pp. 59-72). London: Palgrave Macmillan.

Shepherd, L., Spears, R., \& Manstead, A. S. (2013). "This will bring shame on our nation": The role of anticipated group-based emotions on collective action. Journal of Experimental Social Psychology, 49(1), 42-57.

Sweeny, R. C. (1993). Time and human agency: A re-assessment of the Annales legacy. Left History, 1(2), 63-83.

Smith, E. R. (1993). Social Identity and Social Emotions: Toward New Conceptualizations of Prejudice. In D. M. Mackie and D. L. Hamilton (Eds.). Affect, Cognition and Stereotyping (p. 297-315). San Diego: Academic Press.

Tajfel, H. (Ed.). (1982). Social identity and intergroup relations. New York: Cambridge University Press.

Tint, B. (2010). History, memory, and intractable conflict. Conflict Resolution Quarterly, 27(3), 239-256.

Vollhardt, J. R., \& Bilewicz, M. (2013). After the genocide : Psychological perspectives on victim, bystander, and perpetrator groups. Journal of Social Issues, 69, 1-15.

Volpato, C., Andrighetto, L., Mari, S., Gabbiadini, A., \& Durante, F. (2012). "Italiani brava gente." Effetti di un mito storico sulle relazioni sociali contemporanee [Italians as good fellows. Effects of an historical myth on contemporary social relationships]. In A. Miglietta \& S. Gattino (Eds.), Dietro il pregiudizio. Il contributo della psicologia sociale all'analisi di una società multiculturale [Beyond Prejudice, the contribution of social psychology to the analysis of multicultural society] (pp. 137-150). Napoli: Liguori.

Wojcik, A., Bilewicz, M., \& Lewicka, M. (2010). Living on the ashes: Collective representations of Polish-Jewish history among people living in the former Warsaw Ghetto area. Cities, 27, 195-203. 
Open Access This chapter is licensed under the terms of the Creative Commons Attribution 4.0 International License (http://creativecommons.org/licenses/by/4.0/), which permits use, sharing, adaptation, distribution and reproduction in any medium or format, as long as you give appropriate credit to the original author(s) and the source, provide a link to the Creative Commons license and indicate if changes were made.

The images or other third party material in this chapter are included in the chapter's Creative Commons license, unless indicated otherwise in a credit line to the material. If material is not included in the chapter's Creative Commons license and your intended use is not permitted by statutory regulation or exceeds the permitted use, you will need to obtain permission directly from the copyright holder. 